\title{
Elbow Dislocation with Ipsilateral Radial Shaft Fracture - A Case Report
}

\section{Dislocación del codo con fractura de eje radial ipsilateral - reporte de un caso}

\author{
Marcio Aurelio Aita ${ }^{3}$ Ricardo Kaempf de Oliveira ${ }^{1,2}$ Rafael Pêgas Praetzel ${ }^{1,2}$ Fernando Towata ${ }^{3}$ \\ Pedro Jose Delgado 4 Fabiano da Silva Marques ${ }^{5}$
}

${ }^{1}$ Hospital Santa Casa de Misericórdia, Porto Alegre, RS, Brazil

2 Hospital Mãe de Deus, Porto Alegre, RS, Brazil

${ }^{3}$ Department of Orthopedic and Trauma Surgery, Division of Hand and

Microsurgery, Faculdade de Medicina do ABC, Santo André, SP, Brazil

${ }^{4}$ Universidade CEU San Pablo, Hospital Universitário Madrid

Montepríncipe, Boadilla del Monte, Madrid, Spain

${ }^{5}$ Hospital Santa Casa de Misericórdia, Porto Alegre, RS, Brazil

\begin{abstract}
Address for correspondence Marcio Aurelio Aita, PhD, Division of Hand and Microsurgery, Departamento de Ortopedia e

Traumatologia, Faculdade de Medicina do ABC, Av. Príncipe de Gales, 821 - Príncipe de Gales - Santo André, SP, 09060-650, Brazil (e-mail: marcioaita@me.com).
\end{abstract}

Rev Iberam Cir Mano 2019;47:131-136.

\section{Abstract \\ Keywords \\ - dislocations \\ - elbow joint \\ - fractures \\ - bone \\ - radial fractures}

Resumen
Background Posterior dislocation of the elbow associated to a radial shaft fracture is a rare lesion, its treatment is difficult and complicated, and the indications, surgical options, and timing of surgery may vary. In the present case, we performed immediately after the trauma (urgent care) an open reduction internal fixation (ORIF) surgery of the radial fracture by means of a $3.5 \mathrm{~mm}$ locking plate, associated to closed elbow reduction and stabilization with dynamic bracing.

Case Report A 26-year-old woman was seen in our service with a traumatic deformity of her right, dominant forearm and elbow after a fall from a balance board and presented with a radial shaft fracture and posterior elbow dislocation. The palmar approach was used and the shaft fracture was fixated. During the radial fracture reduction maneuver, the dislocation of the elbow was spontaneously reduced. At 1 year postoperatively, the patient showed good wrist, forearm, and elbow range of motion (ROM). Disabilities of the arm, shoulder and hand (DASH) score of 5 , visual analogue scale (VAS) of 0 , and grip strength of $92 \%$, as compared with the nonaffected side.

Clinical Relevance Nowadays, case reports of concomitant, ipsilateral multiple injuries that uncommonly occur together in a single traumatic episode are very rare. The awareness of this association for early recognition is of paramount significance for ideal clinical results.

Antecedentes La dislocación posterior del codo asociada a una fractura del eje radial es una lesión rara, su tratamiento es difícil y complicado, y las indicaciones, las opciones received

November 21, 2018

accepted

March 25, 2019
DOI https://doi.org/

10.1055/s-0039-1688568. ISSN 1698-8396.
Copyright $\odot 2019$ Thieme Revinter

Publicações Ltda, Rio de Janeiro, Brazil
License terms

(c) (i) $\ominus$ (\$) 
Palabras clave

- dislocaciones

- articulación del codo

- fracturas

- hueso

- fracturas radiales quirúrgicas y el momento de la cirugía pueden variar. En el presente caso, realizamos inmediatamente después del traumatismo (atención de urgencia) una cirugía de fijación interna con reducción abierta (ORIF) de la fractura radial mediante una placa de bloqueo de $3,5 \mathrm{~mm}$, asociada a la reducción y estabilización del codo cerrado con refuerzo dinámico. Reporte de caso Una mujer de 26 años fue atendida en nuestro servicio con una deformidad traumática de su derecha, antebrazo dominante y codo después de una caída de una tabla de equilibrio y se presentó con una fractura del eje radial y dislocación posterior del codo. Se utilizó el abordaje palmar y se fijó la fractura del eje. Durante la maniobra de reducción de la fractura radial, la dislocación del codo se redujo espontáneamente. Al año de la operación, el paciente mostró una buena movilidad de la muñeca, el antebrazo y el codo (ROM). La disability for arm, shoulder and hand questionnaire (DASH) obtuvo una puntuación de 5 , una escala analógica visual (VAS) de 0 y una fuerza de agarre del $92 \%$, en comparación con el lado no afectado.

Relevancia clínica En la actualidad, los informes de casos de lesiones múltiples ipsilaterales concomitantes que ocurren de manera poco común en un solo episodio traumático son muy raros. El conocimiento de esta asociación para el reconocimiento temprano es de suma importancia para los resultados clínicos ideales.

\section{Introduction}

Posterior dislocation of the elbow associated to a radial shaft fracture is a rare lesion, found in only three records in the literature. ${ }^{1-3}$ It can be diagnosed by loss of forearm rotation, wrist and elbow instability and, sometimes, can be associated with pain and nerve injuries.

In the present case, we performed immediately after the trauma (urgent care) an open reduction internal fixation
(ORIF) surgery of the radial fracture by means of a locking plate, associated to closed elbow reduction and stabilization with dynamic bracing.

\section{Case Report}

A 26-year-old woman was seen in our service with a traumatic deformity of her right, dominant forearm and elbow after a fall from a balance board. The range of motion (ROM) of the elbow
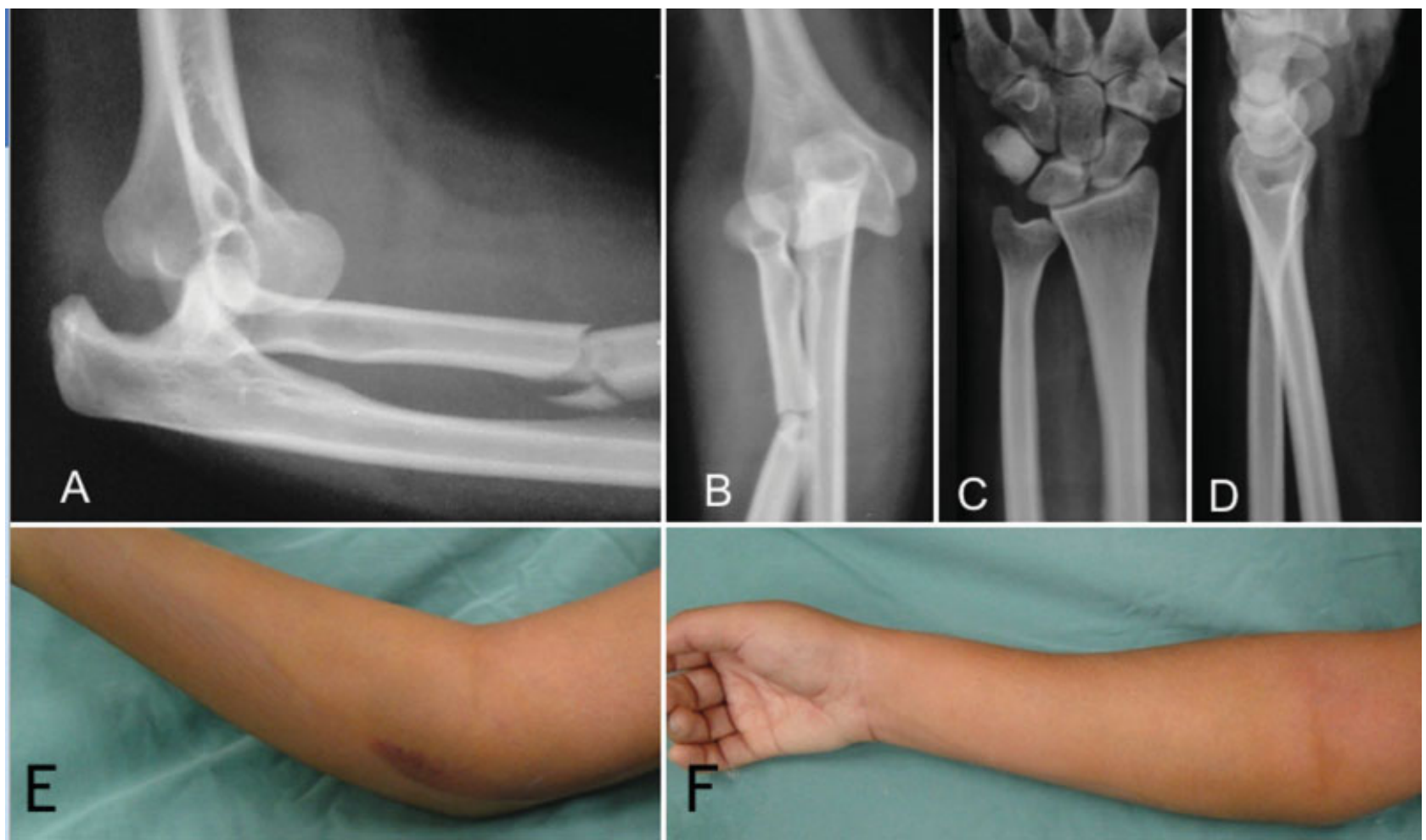

Fig. 1 Preoperative aspects. 


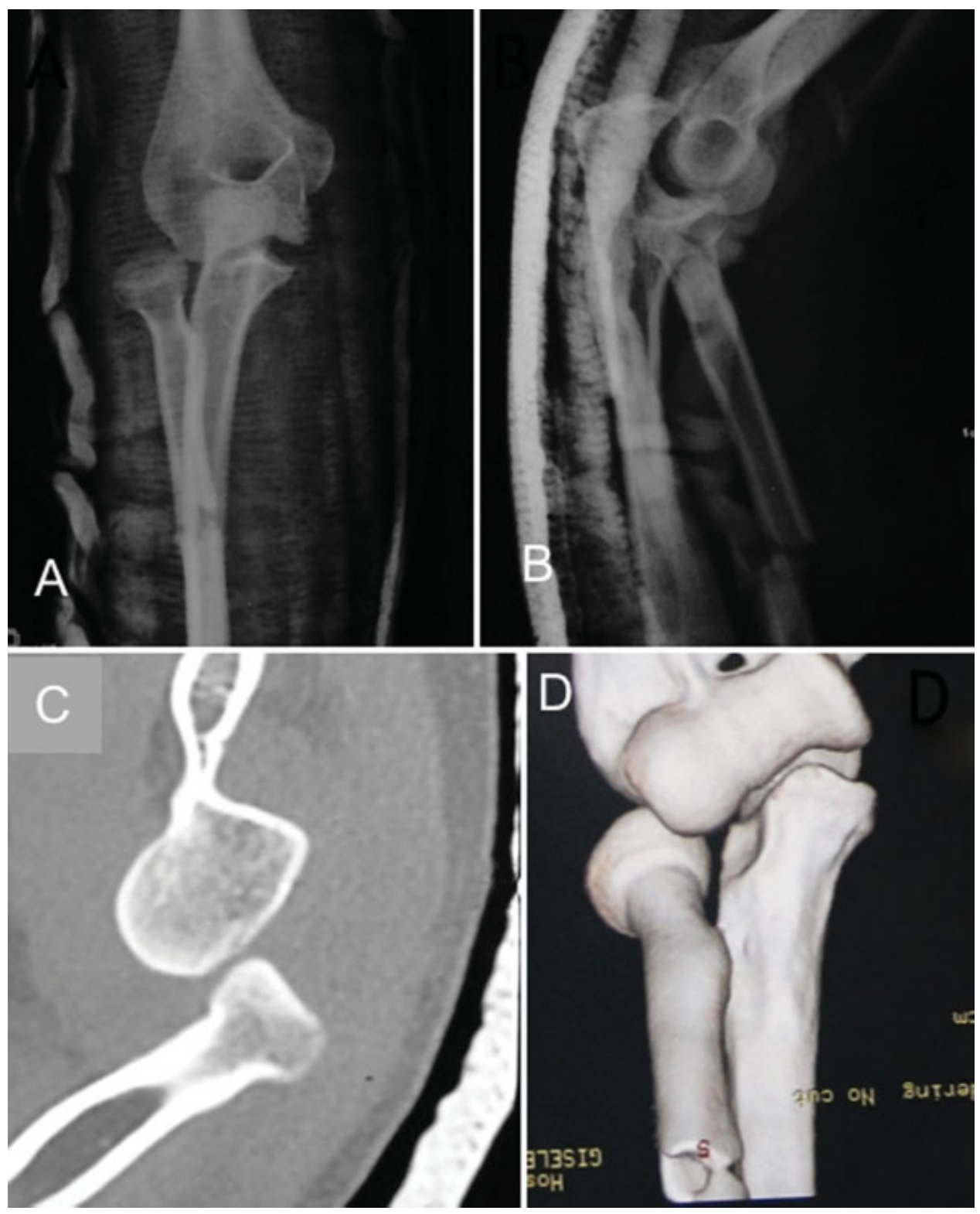

Fig. 2 Preoperative aspects.

was overall limited. Forearm swelling and deformity were present. Neurovascular testing showed abnormal radial nerve sensitivity at the forearm zone, but upper limb perfusion was deemed as normal (-Fig. 1E and F).

Elbow, forearm and wrist radiographs ( - Fig. 1 A to $\mathbf{D}$ ), and associated elbow 3D computed tomography (CT) reconstructed images (-Fig. 2) showed a radial shaft fracture and posterior dislocation of the elbow. There were no other injuries in the wrist or in the elbow.

The initial treatment was performed in the emergency room; however, the dislocation of the elbow could not be reduced, and, at that moment, the medical team decided to perform surgical treatment. The patient was positioned in the supine position, and the upper limb was supported on a specific hand table; brachial plexus anesthesia and sedation were employed.

A Henry approach was used to reach the radial shaft fracture, which was reduced and fixated with a $3.5-\mathrm{mm}$ locked plate, and six Synthes locking screws (Depuy Synthes, Raynham, MA, USA). During the radial fracture reduction maneuver, the dislocation of the elbow was spontaneously reduced. Due to the anatomic reduction, sufficient stabilization, and vascular bone fragment status, the medical team decided not to use bone grafting ( - Fig. $\mathbf{3 A}$ and $\mathbf{B}$ ).

After the surgery, cast mobilization for the right upper limb was employed, and the patient remained in hospital for 2 days. The first dressing change occurred 7 days postoperatively, and by that time the patient had already shown partial improvement of the radial nerve paresthesia, along with good active and passive ROM of the elbow and of the forearm. On the same day, the patient was referred to the rehabilitation sector, and dynamic elbow bracing was placed, thus allowing complete elbow flexion with a restriction of the last $30^{\circ}$ of extension (-Fig. 3C). The patient continuously wore this bracing for 3 weeks, removing only for hygiene and physical therapy 


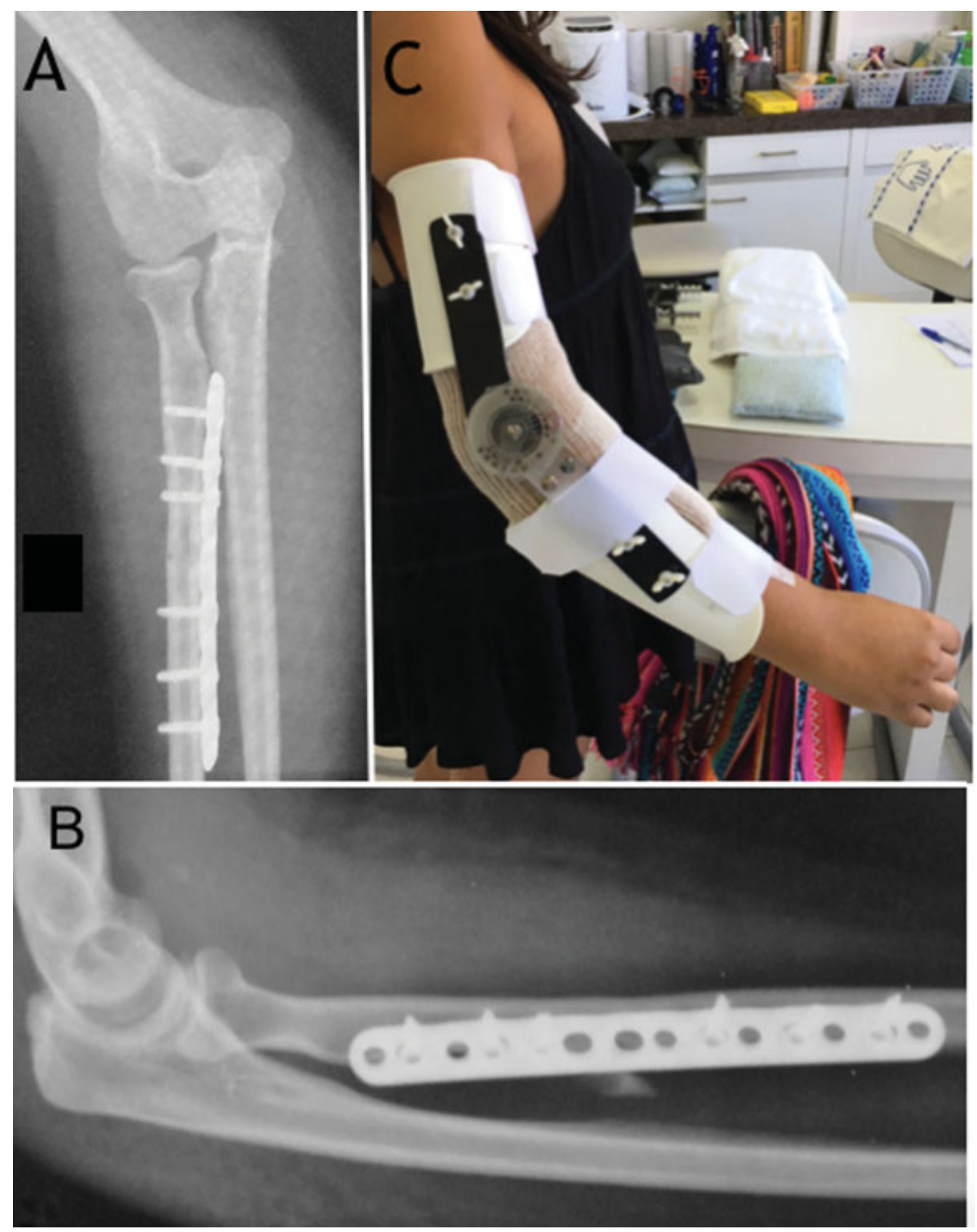

Fig. 3 Postoperative aspects.

sessions. Daily sessions of rehabilitation lasted for 3 months, and then the patient could be allowed to start physical activities.

At 1 year postoperatively, the patient showed good wrist, forearm, and elbow ROM, attaining $70^{\circ}$ of flexion, $60^{\circ}$ of extension, $20^{\circ}$ of radial deviation, $30^{\circ}$ of ulnar deviation, $60^{\circ}$ of pronation, $90^{\circ}$ of supination, $120^{\circ}$ of elbow flexion, and total elbow extension ( - Fig.4). The motion of all fingers was normal. A disabilities of the arm, shoulder and hand (DASH) score of 5 , visual analogue scale (VAS) of 0 , and grip strength of $92 \%$, as compared with the nonaffected side, were obtained. Radiographs indicated healing of the radial fracture, with adequate elbow congruity, and satisfactory radiographic parameters.

\section{Discussion}

The treatment of dislocation of the elbow associated to ipsilateral forearm fractures is difficult and complicated, and the indications, surgical options, and timing of surgery may vary. Closed reduction of dislocation of the elbow and perfect, anatomical reduction of the radial shaft fracture prevent further deformity, stiffness, and loss of motion. ${ }^{1-3}$

Ring et $\mathrm{al}^{4}$ pointed out that isolated fractures of the radial shaft are more common than the true Galeazzi fractures, and surgeons should not overlook the injury to the distal or proximal radioulnar joint in association to isolated diaphyseal fractures of the radius (clinical and radiographs examinations of the forearm must always include the elbow and the wrist). Nonetheless, these lesions can be treated without a specific approach of the distal radioulnar joint (DRUJ) with immediate mobilization. In the present case, after stabilization of the radial shaft fracture, the dislocation of the elbow was spontaneously reduced, and stability was attained.

We agree that the dislocation of the elbow has a different trauma mechanism from the transverse, radial shaft 


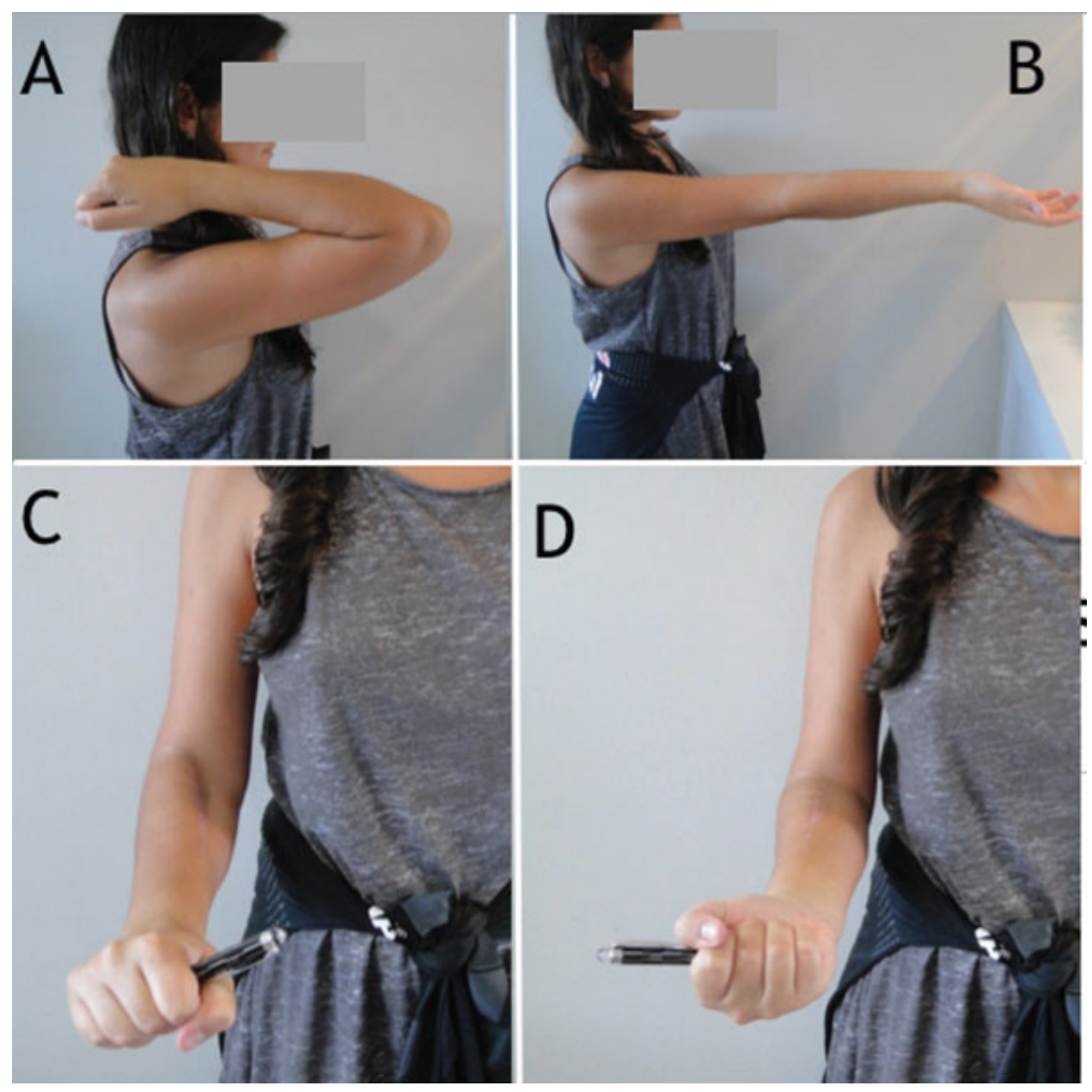

Fig. 4 Clinical results.

fractures, and our search did not produce any link for the single trauma. Therefore, we consider that the best answer consists of two trauma mechanisms, with treatment ensued at the same time.

Beach et al, ${ }^{1}$ in 1966 , suggested nonoperative treatment. However, nowadays, surgical treatment is preferred. In the present case, we chose anatomical reduction, sufficient stabilization, and early mobilization, with complete healing. In the present case, successful clinical results with no complications were seen at 12 months.

Soon et $\mathrm{al}^{2}$ reported complications in a 25 -year-old man with a similar injury (dislocation of the elbow and radial shaft fracture associated with lesion of the ligament in the proximal radioulnar joint). In the first procedure, after the radial fixation, the olecranon reduced, but the radial head kept dislocating. The problem was solved after a further procedure, with the correction of the rotation of the radial fracture and the reconstruction of the ring ligament.

Nowadays, case reports of concomitant, ipsilateral multiple injuries that uncommonly occur together in a single traumatic episode are very rare. The awareness of this association for early recognition is of paramount significance for ideal clinical results. ${ }^{5}$ In the present case report, after 1 year, the patient had no pain, and had attained the same
ROM as compared with the nonaffected side. Radiographs showed full healing of the fracture with adequate DRUJ and elbow joint congruity.

Note

The research presented here was approved by and was in accordance with the ethical standards of the Faculdade de Medicina do ABC Ethics Committee on human experimentation under the number 160/2007. An informed consent document was provided to the patient, who read and signed it according to her will.

\section{Ethical Approval}

The research presented here was approved by and was in accordance with the ethical standards of Ethics Committee of the Faculdade de Medicina do ABC on human experimentation

\section{Informed Consent}

An informed consent document was provided to all research participants, who read and signed it according to their will.

Funding

None. 
Conflicts of Interests

The authors have no conflicts of interests to declare.

\section{Acknowledgments}

Translation service provided by Sandra Miaguti.

\section{References}

1 Beach PM Jr, Hewson JS. Elbow dislocation with comminuted fracture of the proximal radial shaft. Thoughts on the mechanism. Am J Surg 1966;112(06):941-942
2 Soon JC, Kumar VP, Satkunanartham K. Elbow dislocation with ipsilateral radial shaft fracture. An unusual outcome. Clin Orthop Relat Res 1996;(329):212-215

3 Bíró B, Barcsa C. [Elbow dislocation complicated by diaphyseal fracture of the radius]. Magy Traumatol Orthop Helyreallito Seb 1973;16(03):219-221

4 Ring D, Rhim R, Carpenter C, Jupiter JB. Isolated radial shaft fractures are more common than Galeazzi fractures. J Hand Surg Am 2006;31 (01):17-21

5 Abutalib RA, Khoshhal KI. Multiple Concomitant Injuries in One Upper Extremity: A Case Report. Am J Case Rep 2016;17: 6-11 